\title{
The Role of Growth Hormone and IGF-1 in Retinopathy: A Prospective Study of Retinopathy in Patients with Acromegaly and Impaired Fasting Glucose
}

\section{Tzu-En Wu}

Shin Kong Wu Ho Su Memorial Hospital

Harn-Shen Chen ( $\nabla$ chenhs@vghtpe.gov.tw )

Taipei Veterans General Hospital Taoyuan Branch

\section{Research}

Keywords: Acromegaly, growth hormone, IGF-1, impaired fasting glucose, proliferative retinopathy

Posted Date: October 1st, 2021

DOI: https://doi.org/10.21203/rs.3.rs-530165/v2

License: (1) This work is licensed under a Creative Commons Attribution 4.0 International License. Read Full License

Version of Record: A version of this preprint was published at Diabetology \&amp; Metabolic Syndrome on March 5th, 2022. See the published version at https://doi.org/10.1186/s13098-022-00806-z. 


\section{Abstract}

\section{Aims}

To investigate the effects of the GH-IGF-1 axis on the incidence and progression of retinopathy.

\section{Methods}

We enrolled 91 patients with acromegaly and 123 subjects with impaired fasting glucose (IFG) between 2008 and 2016 to examine the incidence and prevalence of retinopathy. Patients attended follow-ups in our clinics and underwent examinations according to the national guidelines for diabetes management. Both cohorts attended follow-ups until June 2019.

\section{Results}

Both groups had similar $\mathrm{HbA} 1 \mathrm{c}$, cholesterol, and blood pressure levels. However, patients with acromegaly had higher GH $(8.05 \pm 16.18 \mathrm{vs}$. $0.78 \pm 1.25 \mathrm{ng} / \mathrm{mL})$ and IGF-1 ( $547.0 \pm 342.1 \mathrm{vs.} 146.7 \pm 51.4 \mathrm{ng} / \mathrm{mL}$ ) levels than in subjects with IFG. During the follow-up period, eight patients $(8.8 \%)$ with acromegaly and 12 patients $(9.8 \%)$ with IFG developed some degree of retinopathy. Three patients with acromegaly and two with IFG progressed to proliferative retinopathy. Patients with acromegaly had the same incidence of non-proliferative retinopathy (odds ratio [OR]: $0.830 ; 95 \% \mathrm{Cl}: 0.318-2.164)$ and a non-statistically significantly higher incidence of proliferative retinopathy (OR: 2.461 ; 95\% Cl: 0.404-14.988).

\section{Conclusion}

The data reveals that GH and IGF-1 might play a crucial role in the development of proliferative retinopathy and influence its progression. Therefore, we suggest screening patients with acromegaly should be similar to diabetes patients.

\section{Introduction}

Acromegaly is a rare chronic disorder characterized by excessive growth hormone (GH) and insulin-like growth factor 1 (IGF-1) secretion. More than $95 \%$ of acromegaly cases are caused by pituitary adenomas [1]. The main effects of $\mathrm{GH}$ are mediated by stimulating the production of IGFs [2]. IGF-1 modulates the function of retinal endothelial precursor cells, drives retinal angiogenesis in response to hypoxia, and may play a role in the pathogenesis of proliferative diabetic retinopathy [3]. In addition, there is a large amount of data indicating that an increase in IGF-1 activity may contribute to retinal neovascularization, which is a characteristic sign of proliferative diabetic retinopathy [4-5].

Neovascularization is the final common pathway of diabetic retinopathy, and IGF-1 has been associated with retinal neovascularization [6]. There have been reports of spontaneous regression of proliferative diabetic retinopathy in women who develop acute total hypopituitarism. Thus, pituitary ablation may be a treatment for vision-threatening retinopathy $[7,8]$. Even though IGF-1 may play a pathogenic role in diabetic retinopathy, most research has failed to provide any convincing data regarding the relationship between IGF-1 and the development of retinopathy [9-11].

We have previously reported that serum IGF-1 levels are not associated with the incidence of mild-to-moderate or severe retinopathy in patients with type 2 diabetes [12]. However, in patients with adequate blood glucose control, elevated serum IGF-1 levels are associated with higher cumulative incidence of severe retinopathy. Therefore, we propose that glycated hemoglobin (HbA1c) is a main risk factor for retinopathy and serum IGF-1 influences the development of severe diabetic retinopathy. However, this may be masked by poor blood glucose control [12]. In a previous study, we demonstrated a higher incidence of proliferative retinopathy without non-proliferative retinopathy in patients with acromegaly [13].

We hypothesize that IGF-1 can accelerate the progression of retinopathy from non-proliferative to proliferative and shorten the duration of non-proliferative retinopathy. To examine the influence of the GH-IGF-1 axis on retinopathy, we selected patients with impaired fasting glucose (IFG) to serve as the control group. In addition, we investigated the progression of retinopathy from non-proliferative to proliferative and attempted to clarify the nature of the progression in patients with acromegaly. 


\section{Methods \\ Study Participants}

In this prospective, observational study, we recruited 91 patients with acromegaly who were being regularly monitored at our institution (Taipei Veterans General Hospital) between 2008 and 2016. The diagnosis of acromegaly was made based on clinical findings and confirmed with elevated GH and IGF-1 levels. In addition, we enrolled 123 subjects with IFG diagnoses between 2011 and 2014 to serve as the control group. Patients with IFG underwent an oral glucose tolerance test (OGTT) and the development of diabetes and diabetic complications was monitored at follow-ups. Both cohorts attended follow-ups until June 2019. The Institutional Review Board of Taipei Veterans General Hospital approved the study protocols in 2008 and 2011. Written informed consent was obtained from all participants. This study complies with the Strengthening the Reporting of Observational Studies in Epidemiology (STROBE) statement (14) and the broader EQUATOR guidelines [15].

\section{Study protocol}

To assess glucose homeostasis and disease activity, all patients with IFG and a majority of patients with acromegaly (61/91) underwent an OGTT after an overnight fast. After oral administration of 75 grams of glucose, blood was drawn at 0, 30, 60, 90, and 120 minutes. Blood samples from all time points were assayed for insulin and glucose. Additionally, blood samples from patients with acromegaly were also analyzed for $\mathrm{GH}$. IGF-1, GH, and $\mathrm{HbA} 1 \mathrm{c}$ levels at baseline were measured in fasting blood samples. Blood pressure was measured on the same morning the OGTT was performed. All patients had their blood pressure measured from the right arm using an electronic sphygmomanometer while sitting in a relaxed position.

\section{Funduscopic examinations}

We took yearly retinal color photographs of all participants. Photographs were taken with a fundus camera to obtain a central view of the macula and disc at a $45^{\circ}$ angle. The photographs were evaluated by experienced endocrinologists blinded to the patients' medical condition. We classified the severity of the retinopathy into the following four categories: no apparent retinopathy, mild-to-moderate nonproliferative retinopathy, severe non-proliferative retinopathy, and proliferative retinopathy. Patients with abnormal findings were referred to ophthalmologists for further evaluation. These patients underwent further comprehensive retinal examination, fluorescein angiography, and optical coherence tomography if indicated.

\section{Laboratory Analyses}

Serum GH was measured using a sensitive immuno-fluorometric assay (Wallac, Turku, Finland) specific to the 22-kDa GH protein calibrated to the WHO International Reference Preparation 80/505 (detection limit: $0.05 \mu \mathrm{g} / \mathrm{L}$; inter-assay coefficient of variation [CV]: 1.6$8.4 \%$ between 0.5 and $40 \mu \mathrm{g} / \mathrm{L}$ ]. Serum IGF-1 was determined using an immuno-radiometric assay (Diagnostic System Laboratory, Webster, TX, USA) with inter- and intra-assay CVs less than $7.4 \%$ and $7.0 \%$, respectively. HbA1c was measured using high-performance liquid chromatography (HLC-723G7, Tosoh, Japan) with a reference range of $4.2-5.8 \%$.

\section{Statistical Analyses}

The data were analyzed using version 26.0 of IBM SPSS for Windows (SPSS Inc., Chicago, Illinois, USA). All data are expressed as means and standard deviations or as frequencies (percent). The unpaired Student's $t$-test was used to compare continuous parameter data between groups, and the Mann-Whitney U test was used to compare non-parametric data between groups. When appropriate, Carter's test, Yates' correction, or Fisher's exact test were used to compare categorical data between groups. Pearson's $\chi^{2}$ test was used to compare nominal and ordinal data from both groups and is reported as a percentage. Kaplan-Meier estimates were assessed to determine the cumulative probability of retinopathy over time. Cox proportional hazards regression models were used to compare the incidence of retinopathy between the groups.

\section{Results}

\section{Baseline characteristics}

A total of 91 patients (42 men, 49 women) with acromegaly were recruited for this study and the mean age at baseline was $49.9 \pm 16.0$ years. The control group comprised 123 subjects with IFG (33 men, 90 women) and the mean age at baseline was $54.9 \pm 9.7$ years. The baseline clinical and biochemical data of patients with acromegaly and IFG are shown in Table 1. Notably, patients with acromegaly were 
younger, predominantly men, taller, heavier, with a higher BMI and higher GH and IGF-1 levels. However, HbA1c, fasting blood glucose, cholesterol, and blood pressure levels were identical in both groups.

Table 1

Demographic Characteristics of Patients with Acromegaly and Impaired Fasting Blood Glucose

\begin{tabular}{|llll|}
\hline & Acromegaly $(\mathbf{n}=\mathbf{9 1})$ & Patients with Impaired Fasting Blood Glucose $(\mathbf{n}=123)$ & $\boldsymbol{p}$ value \\
\hline Age (years) & $49.9 \pm 16.0$ & $59.4 \pm 9.7$ & $<0.001$ \\
\hline Sex (male/female) & $42 / 49$ & $33 / 90$ & $<0.001^{\#}$ \\
\hline Body Height $(\mathrm{cm})$ & $167.8 \pm 12.1$ & $158.6 \pm 7.5$ & $<0.001$ \\
\hline Body Weight $(\mathrm{kg})$ & $74.0 \pm 17.2$ & $62.3 \pm 10.7$ & $<0.001$ \\
\hline BMl $\left(\mathrm{kg} / \mathrm{m}^{2}\right)$ & $26.20 \pm 4.62$ & $24.75 \pm 3.71$ & 0.013 \\
\hline Systolic BP $(\mathrm{mmHg})$ & $128.3 \pm 16.5$ & $128.3 \pm 14.4$ & 0.989 \\
\hline Diastolic BP $(\mathrm{mmHg})$ & $77.6 \pm 11.8$ & $76.6 \pm 9.2$ & 0.471 \\
\hline Fasting GH $(\mathrm{ng} / \mathrm{mL})$ & $8.05 \pm 16.18$ & $0.78 \pm 1.25$ & $<0.001$ \\
\hline Fasting IGF-1 $(\mathrm{ng} / \mathrm{mL})$ & $547.0 \pm 342.1$ & $146.7 \pm 51.4$ & $<0.001$ \\
\hline Fasting PG $(\mathrm{mg} / \mathrm{dL})$ & $103.6 \pm 20.0$ & $107.8 \pm 10.7$ & 0.408 \\
\hline HbA1c $(\%)$ & $6.22 \pm 1.08$ & $6.12 \pm 0.48$ & 0.383 \\
\hline Cholesterol $(\mathrm{mg} / \mathrm{dL})$ & $186.3 \pm 27.2$ & $184.4 \pm 21.5$ & 0.640 \\
\hline HDL Cholesterol $(\mathrm{mg} / \mathrm{dL})$ & $56.8 \pm 26.1$ & $53.2 \pm 20.5$ & 0.402 \\
\hline Triglycerides $(\mathrm{mg} / \mathrm{dL})$ & $111(86-128.5)$ & $109(79.5-171)$ & $0.299^{*}$ \\
\hline Creatinine $(\mathrm{mg} / \mathrm{dL})$ & $0.78 \pm 0.41$ & $0.70 \pm 0.20$ & 0.087 \\
\hline eGFR (mL/min/1.73 m $\left.{ }^{2}\right)$ & $105.7 \pm 32.4$ & $103.0 \pm 28.5$ & 0.583 \\
\hline Urine Albumin-to-Creatine Ratio $(\mathrm{mg} / \mathrm{gCr})$ & $12.7(4.4-70.1)$ & $6.8(4.85-16.75)$ & $0.230^{*}$ \\
\hline
\end{tabular}

Abbreviations: BP, blood pressure; HbA1c, glycated hemoglobin; PG, plasma glucose; GH, growth hormone. \#Fisher's exact test; *MannWhitney U test.

The plasma glucose and insulin levels during OGTT were presented in the Fig. 1. The subjects with IFG had higher glucose levels after oral glucose loading and higher glucose concentration during OGTT, presented with glucose area under curve (AUC) during OGTT (416.2 \pm 63.7 vs. $373.8 \pm 82.2 \mathrm{mg} / \mathrm{dL}, \mathrm{p}=0.001)$. The subjects with IFG had higher insulin levels at 90 and 120 minutes after glucose loading, however the insulin AUC during OGTT were the same between the two groups (198.9 $\pm 140.7 \mathrm{vs} .186 .6 \pm 177.4 \mathrm{uU} / \mathrm{mL}, \mathrm{p}=0.621)$.

\section{The Cumulative Probability of Retinopathy}

The median follow-up period was 64 months (interquartile range [IQR]: 39-109 months) for patients with acromegaly and 85 months (IQR: 72-94 months) for patients with IFG. During the follow-up period, eight patients (8.8\%) with acromegaly and 12 (9.8\%) with IFG developed some degree of retinopathy (Fig. 2). Table 2 shows the incidence of any retinopathy, non-proliferative retinopathy, and proliferative retinopathy in patients with acromegaly and IFG. Three patients (3.3\%) with acromegaly and two (1.6\%) with IFG progressed to proliferative retinopathy. One patient in each group was diagnosed with proliferative retinopathy with no non-proliferative retinopathy observed during the study period. Although patients with acromegaly had the same incidence of non-proliferative retinopathy (odds ratio [OR]: $0.963 ; 95 \% \mathrm{Cl}: 0.373-2.485)$ and non-statistically significantly higher incidence of proliferative retinopathy (OR: $2.461 ; 95 \% \mathrm{Cl}$; 0.404-14.988). 
Table 2

Incidence of Retinopathy in Patients with Acromegaly $(\mathrm{n}=91)$ and Impaired Fasting Glucose $(\mathrm{n}=123)$

\begin{tabular}{|lllll|}
\hline & Acromegaly & Impaired Fasting Glucose & \\
\hline & $\mathrm{n}(\%)$ & $\mathrm{n}(\%)$ & Odds Ratio & 95\% Confidence Interval \\
\hline No Apparent Retinopathy & $84(92.3)$ & $107(87.0)$ & & 0.963 \\
\hline Any Level of Retinopathy & $8(8.8)$ & $12(9.8)$ & 0.830 & $0.373-2.485$ \\
\hline Non-Proliferative Retinopathy & $7(7.7)$ & $11(8.9)$ & 2.461 & $0.318-2.164$ \\
\hline Proliferative Retinopathy & $3(3.3)$ & $2(1.6)$ & & $0.404-14.988$ \\
\hline
\end{tabular}

Two patients (one with acromegaly and one with impaired fasting glucose) were diagnosed with proliferative retinopathy without a non-proliferative retinopathy stage.

\section{Baseline Clinical Characteristics of Patients with Proliferative Retinopathy}

The baseline clinical and biochemical characteristics of patients who developed proliferative retinopathy during the study period are shown in Table 3. Patients with acromegaly with proliferative retinopathy had higher GH, IGF-1, and HbA1c levels than those without proliferative retinopathy. In contrast, patients with IFG who had proliferative retinopathy had similar GH and IGF-1 levels and traditional risk factors for retinopathy compared to those without proliferative retinopathy.

Table 3

Baseline Clinical Characteristics of Patients with Proliferative Retinopathy

\begin{tabular}{|c|c|c|c|c|c|c|c|c|c|c|}
\hline & $\begin{array}{l}\text { Age } \\
\text { (years) }\end{array}$ & Sex & $\begin{array}{l}\text { Fasting } \\
\mathrm{GH} \\
(\mathrm{ng} / \mathrm{mL})\end{array}$ & $\begin{array}{l}\text { Fasting } \\
\text { IGF-1 } \\
\text { (ng/mL) }\end{array}$ & $\begin{array}{l}\text { HbA1c } \\
(\%)\end{array}$ & $\begin{array}{l}\text { Systolic } \\
\text { BP } \\
(\mathrm{mmHg})\end{array}$ & $\begin{array}{l}\text { Diastolic } \\
\text { BP } \\
(\mathrm{mmHg})\end{array}$ & $\begin{array}{l}\text { Cholesterol } \\
\text { (mg/dL) }\end{array}$ & $\begin{array}{l}\text { Triglycerides } \\
\text { (mg/dL) }\end{array}$ & $\begin{array}{l}\text { UACR } \\
(\mathrm{mg} / \mathrm{gCr})\end{array}$ \\
\hline $\begin{array}{l}\text { Acromegaly- } \\
04\end{array}$ & 34 & Female & 17.9 & 1840 & 7.9 & 124 & 77 & 190 & 96 & 92.6 \\
\hline $\begin{array}{l}\text { Acromegaly- } \\
52\end{array}$ & 55 & Female & 15.4 & 1055 & 6.9 & 114 & 69 & 163 & 101 & 15.8 \\
\hline $\begin{array}{l}\text { Acromegaly- } \\
54\end{array}$ & 58 & Female & 34.2 & 906 & 7.1 & 120 & 61 & 172 & 62 & 12.2 \\
\hline $\begin{array}{l}\text { Impaired } \\
\text { Fasting } \\
\text { Glucose-307 }\end{array}$ & 61 & Female & 0.3 & 123 & 6.6 & 154 & 82 & 78 & 72 & 16.7 \\
\hline $\begin{array}{l}\text { Impaired } \\
\text { Fasting } \\
\text { Glucose-428 }\end{array}$ & 72 & Male & 0.1 & 138 & 6.2 & 112 & 67 & 228 & 312 & 5.2 \\
\hline
\end{tabular}

Abbreviations: HbA1C, glycated hemoglobin; GH, growth hormone; BP, blood pressure; UACR, Urine Albumin-to-Creatine ratio (mg/gCr).

\section{Discussion}

We followed 91 patients with acromegaly and 123 patients with IFG for more than eight years to study and compare the incidence of retinopathy in patients with abnormal glucose homeostasis, who are thus at risk for developing retinopathy. To the best of our knowledge, this is the first study to compare the incidence of retinopathy in these patients. Both groups had similar $\mathrm{HbA1c}$, cholesterol, and blood pressure levels. A significant intergroup difference was higher $\mathrm{GH}(8.05 \pm 16.18 \mathrm{vs} .0 .78 \pm 1.25 \mathrm{ng} / \mathrm{mL})$ and IGF-1 (547.0 $\pm 342.1 \mathrm{vs}$. $146.7 \pm 51.4 \mathrm{ng} / \mathrm{mL}$ ) levels in patients with acromegaly. During the follow-up period, eight patients with acromegaly (8.8\%) and $12 \mathrm{with}$ IFG (9.8\%) developed some degree of retinopathy. Three patients with acromegaly (3.3\%) and two with IFG (1.6\%) progressed to proliferative retinopathy. Patients with acromegaly were noted to have the same incidence of non-proliferative retinopathy (OR: 0.830; $95 \% \mathrm{Cl}$ : 0.3182.164) and a non-statistically significantly higher incidence of proliferative retinopathy (OR: 2.461, 95\%; Cl: 0.404-14.988).

Retinopathy is the most common complication in diabetes patients and can even develop during the prediabetes stage. Patients with acromegaly usually have elevated GH and IGF-1 levels, which can lead to insulin resistance and diabetes [16]. GH has been considered pathogenic for diabetes for nearly a century, and excessive GH secretion can cause microvascular complications, like retinopathy [17]. Füchtbauer et al. (2020) conducted a study to evaluate the morphology of retinal vessels in patients with acromegaly and the prevalence 
of diabetic retinopathy in patients with acromegaly and diabetes [18]. They reported a higher number of retinal blood vessel branches in patients with acromegaly. However, there was not a high prevalence of diabetic retinopathy in patients with acromegaly and diabetes [18].

Risk factors for diabetic retinopathy include the time since onset of diabetes, high blood glucose, high blood pressure, dyslipidemia, and insulin resistance $[19,20]$. Yau et al. (2012) conducted a systematic study to examine the overall prevalence and risk factors for diabetic retinopathy in patients with diabetes [21]. The overall prevalence of any retinopathy was $34.6 \%$, and the prevalence of proliferative retinopathy was $6.96 \%$. The prevalence increase was associated with the time since onset of diabetes and $\mathrm{HbA} 1 \mathrm{c}$ and blood pressure levels [21]. Song et al. (2018) conducted a systematic review and meta-analysis to investigate the prevalence and risk factors for retinopathy in China [22]. The observed prevalence for retinopathy was $1.14 \%$ in the general population and $0.07 \%$ for proliferative retinopathy. In patients with diabetes, the combined prevalence for any retinopathy was $18.45 \%$, and the combined prevalence for proliferative retinopathy was $0.99 \%$ [22]. We retrospectively analyzed 43 patients with acromegaly and 129 age- and gender-matched type 2 diabetes patients [13]. We found that $9.3 \%$ of patients with acromegaly (4/43) and $9.3 \%$ of patients with type 2 diabetes (12/129) had proliferative retinopathy. However, non-proliferative retinopathy was not observed in patients with acromegaly, while it was observed in $25.9 \%$ of patients with type 2 diabetes (33/129) [13]. Even though non-proliferative retinopathy is not observed in patients with acromegaly, the frequency of proliferative retinopathy is the same as in patients with type 2 diabetes [13]. Füchtbauer et al. (2020) conducted a cross-sectional study to assess the prevalence of retinopathy in 39 patients with long-term acromegaly and diabetes in Sweden [18]. They diagnosed five cases (13\%) of retinopathy (two cases of proliferative diabetic retinopathy and three cases of proliferative diabetic retinopathy) and concluded that the prevalence of retinopathy is not higher in patients with acromegaly compared to patients with diabetes [18]. In the current eight-year follow-up study, retinopathy was diagnosed in eight patients (8.8\%) with acromegaly and 12 patients $(9.8 \%)$ with IFG. According to our research and previous reports, we may assume that the prevalence of non-proliferative retinopathy in patients with acromegaly is higher than in the general population, lower than in patients with diabetes, and the same as in patients with IFG $[13,19-22]$. Additionally, the prevalence of proliferative retinopathy in patients with acromegaly is higher compared to the general population and patients with prediabetes and may be similar to the prevalence in patients with diabetes [13, 19-22].

This study's strengths include the recruitment of a relatively high number of patients with acromegaly and the regular follow-ups. This study is the first to compare the prevalence of retinopathy in patients with acromegaly and IFG. Both groups had identical major risk factors for retinopathy as reflected by their $\mathrm{HbA1c}$, cholesterol, and blood pressure levels. The only significant intergroup difference was their GH and IGF-1 levels, enabling us to precisely investigate their effects on retinopathy development. Nevertheless, our study was limited by presenting only a small event rate for proliferative retinopathy, which prevents confirmation of our hypothesis. Therefore, including more participants and a longer follow-up period is required to confirm our hypothesis.

In conclusion, although not statistically significant, patients with acromegaly appear to have the same incidence of non-proliferative retinopathy and a non-statistically significantly higher incidence of proliferative retinopathy compared to patients with IFG. Our data revealed that GH or IGF-1 may play a crucial role in the development of proliferative retinopathy and may influence the progression of retinopathy. Although a future study with more patients and a longer follow-up period is warranted, the data suggest that patients with acromegaly, like patients with diabetes, should be screened for retinopathy.

\section{Declarations}

\section{Ethics approval and consent to participate}

The Institutional Review Board of Taipei Veterans General Hospital approved the study protocols in 2008 and 2011. Written informed consent was obtained from all participants.

\section{Consent for publication}

I and my co-authors have agreed to transfer the copyrights to the publisher, if the manuscript is accepted for publication.

\section{Availability of data and materials}

Supplemental data with the file name of Acromegaly (6) and IFG has GH data 2021-04.pdf

\section{Competing interests}

The authors declare no conflict of interest. 
This study was supported by grants from the Taiwan Ministry of Science and Technology (MOST 105-2314-B-010-037-MY3) and the Taipei Veterans General Hospital (V107C-066).

\section{Authors' contributions}

TEW evaluated fundus photographs, wrote the manuscript, and contributed to the discussion. HSC contributed to the research design, analyzed the research data, edited the manuscript, and is responsible for the content presented in this article.

\section{Acknowledgements}

We would like to thank Uni-edit (www.uni-edit.net) for editing and proofreading this manuscript.

\section{References}

1. Melmed S (2006) Medical progress: Acromegaly. N Engl J Med. 355(24): 2558-73.

2. Van Wyk JJ, Svoboda ME, Underwood LE (1980) Evidence from radioligand assays that somatomedin-C and insulin-like growth factor-I are similar to each other and different from other somatomedins. J Clin Endocrinol Metab. 50(1): 206-8.

3. Cheung N, Mitchell P, Wong TY. Diabetic retinopathy (2010) Lancet. 376(9751): 124-36.

4. Smith LE, Shen W, Perruzzi C, Soker S, Kinose F, Xu X et al (1999) Regulation of vascular endothelial growth factor-dependent retinal neovascularization by insulin-like growth factor-1 receptor. Nat Med 5(12): 1390-1395.

5. Kondo T, Vicent D, Suzuma K, Yanagisawa M, King GL, Holzenberger M, Kahn CR (2003) Knockout of insulin and IGF-1 receptors on vascular endothelial cells protects against retinal neovascularization. J Clin Invest. 111(12):1835-42.

6. Smith LE, Kopchick JJ, Chen W, et al. (1997) Essential role of growth hormone in ischemia-induced retinal neovascularization. Science 276(5319): 1706-1709.

7. Poulsen JE (1953) Recovery from retinopathy in a case of diabetes with Simmonds' disease. Diabetes 2(1):7-12.

8. Teuscher A, Escher F, Konig H \& Zahnd G (1970) Long-term effects of transsphenoidal hypophysectomy on growth hormone, renal function and eyeground in patients with diabetic retinopathy. Diabetes 19(7): 502-518.

9. Dills DG, Moss SE, Klein R, Klein BE, Davis M (1990) Is insulin like growth factor I associated with diabetic retinopathy? Diabetes. 39(2): 191-5.

10. Wang Q, Dills DG, Klein R, Klein BE, Moss SE (1995) Does insulin-like growth factor I predict incidence and progression of diabetic retinopathy? Diabetes. 44(2): 161-4.

11. Frystyk J. The growth hormone hypothesis - 2005 revision (2005) Horm Metab Res. 37(Suppl 1): 44-8.

12. Chen HS, Wu TE, Hsiao LC, Lin SH (2012) Interaction between glycaemic control and serum insulin-like growth factor 1 on the risk of retinopathy in type 2 diabetes. Eur J Clin Invest. 42(4): 447-54

13. Wu TE, Chen HS (2018) Increased prevalence of proliferative retinopathy in patients with acromegaly. J Chin Med Assoc. 81(3): 230235.

14. von Elm E, Altman DG, Egger M, et al.(2007) The Strengthening the Reporting of Observational Studies in Epidemiology (STROBE) statement: guidelines for reporting observational studies. Lancet 370(9596): 1453-1457.

15. EQUATOR Network. Enhancing the QUAlity and Transparency Of health Research. http://www. equator-network.org (accessed Dec 25, 2008).

16. Frara S, Maffezzoni F, Mazziotti G, Giustina A (2016). Current and Emerging Aspects of Diabetes Mellitus in Acromegaly. Trends Endocrinol Metab. 27(7): 470-483

17. Sperling MA (2016) Traditional and novel aspects of the metabolic actions of growth hormone. Growth Horm IGF Res. 28: 69-75

18. Füchtbauer LM, Olsson DS, Coopmans EC, Bengtsson BÅ, Norrman LL, Neggers SJCMM, Hellstrom A, Johannsson G (2020) Increased Number of Retinal Vessels in Acromegaly. Eur J Endocrinol. 182(3): 293-302

19. Solomon SD, Chew E, Duh EJ, Sobrin L, Sun JK, VanderBeek BL, Wykoff CC, Gardner TW (2017) Diabetic Retinopathy: A Position Statement by the American Diabetes Association. Diabetes Care. 40(9): 412-418.

20. Antonetti DA, Klein R, Gardner TW (2012). Diabetic retinopathy. N Engl J Med. 366(13): 1227-39.

21. Yau JWY, Rogers SL, Kawasaki R, et al. (2012) Meta-Analysis for Eye Disease (META-EYE) Study Group. Global prevalence and major risk factors of diabetic retinopathy. Diabetes Care 35(3): 556-564 
22. Song P, Yu J, Chan KY, Theodoratou E, Rudan I (2018). Prevalence, risk factors and burden of diabetic retinopathy in China: a systematic review and meta-analysis. J Glob Health. 8(1): 010803

\section{Figures}

Figure 1A. Plasma glucose levels during OGTT

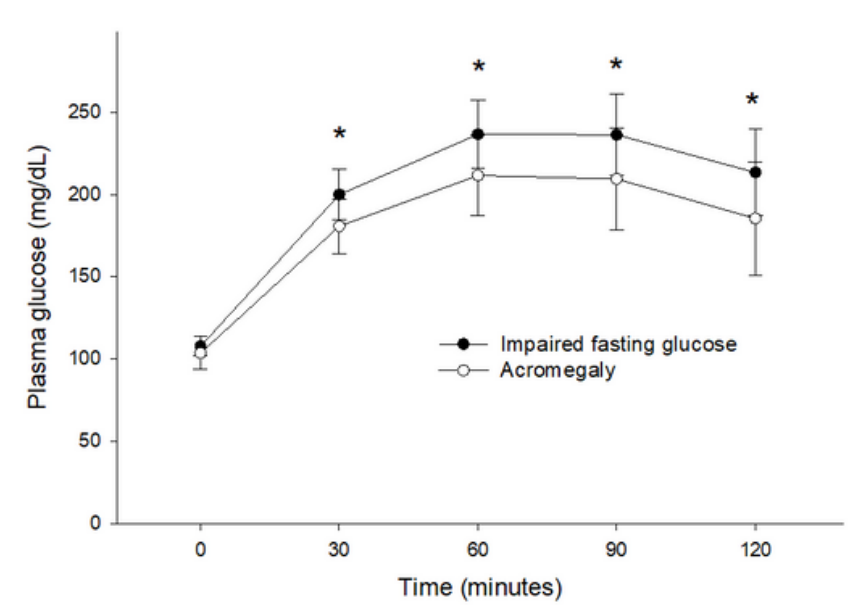

Figure 1B. Plasma insulin levels during OGTT

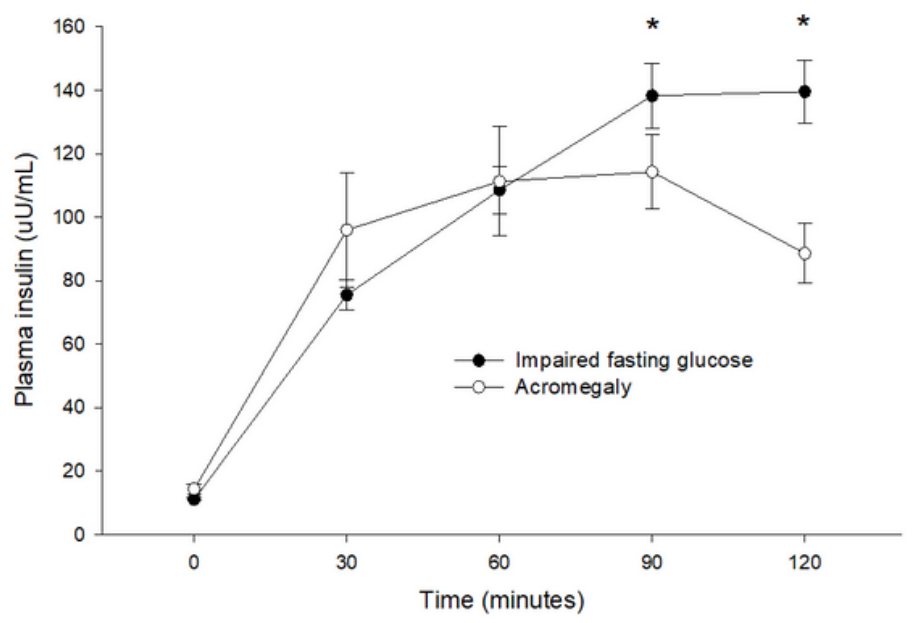

\section{Figure 1}

Plasma glucose (A) and insulin (B) concentrations during the OGTT in patients with acromegaly and subjects with IFG. $\left({ }^{*} \mathrm{p}<0.05\right.$ between groups). 


\section{Figure 2.}

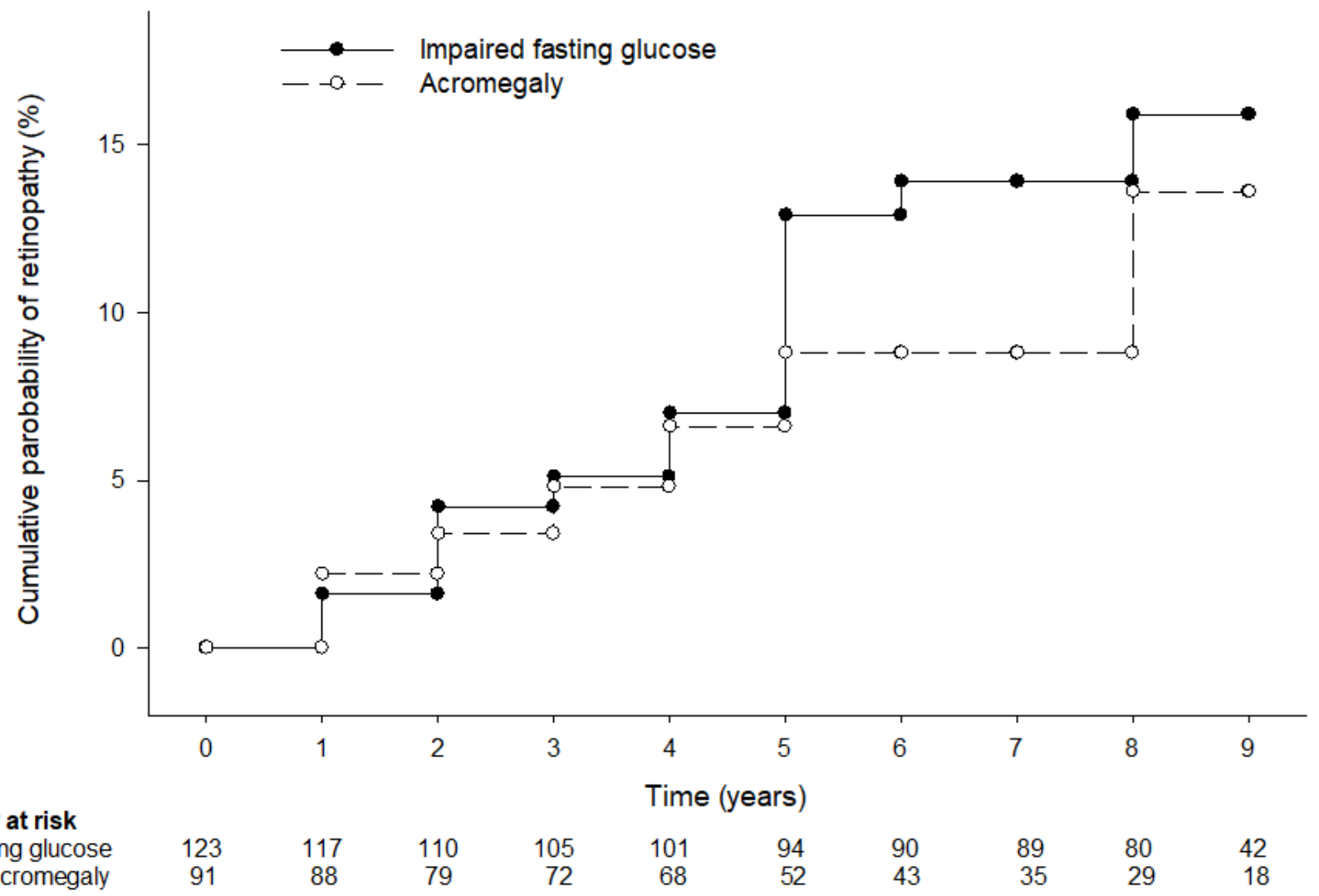

\section{Figure 2}

Cumulative probability of retinopathy in patients with acromegaly and subjects with IFG during the eight-year follow-up period

\section{Supplementary Files}

This is a list of supplementary files associated with this preprint. Click to download.

- Acromegaly6andIFGhasGHdata202104.pdf

- STROBEchecklistcohortforAcromegalyandEye202109.docx 